\title{
Corrosion Resistance of Titanium-Magnesium Alloy in Weak Acid Solution Containing Fluoride Ions
}

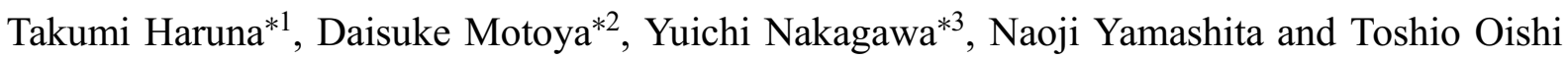 \\ Department of Materials Science and Engineering, Faculty of Engineering, Kansai University, Suita 564-8680, Japan
}

We have developed Ti-Mg alloy for dental material corrosion-resistant to aqueous fluoride solutions. Ti plates and granular Mg was put in a sealed vessel and heated at $950^{\circ} \mathrm{C}$, so Ti plates were exposed in the liquid and the vapor $\mathrm{Mg}$ phases. The conditions made $\mathrm{Mg}$ diffuse into the Ti plates to produce $\mathrm{Ti}-\mathrm{Mg}$ alloy. The $\mathrm{Ti}-\mathrm{Mg}$ alloy produced in the vapor $\mathrm{Mg}$ phase for $430 \mathrm{~h}$ achieved homogeneous distribution in $\mathrm{Mg}$ concentration of 0.2 at\%. A Vickers micro hardness increased almost linearly with an increase in the Mg concentration, and the hardness of the homogeneous $\mathrm{Ti}-0.2$ at $\% \mathrm{Mg}$ was about 1.2 times larger than that of Ti before alloying. It was confirmed that corrosion resistance of Ti in the fluoride solution was improved by alloying with $\mathrm{Mg}$. The method using the vapor $\mathrm{Mg}$ phase contributed much more effective improvement of corrosion resistance than that using the liquid phase. The homogeneous Ti- 0.2 at $\% \mathrm{Mg}$ demonstrated a maximum corrosion resistance of all the specimens, by about 80 times to Ti. [doi:10.2320/matertrans.MC201210]

(Received July 10, 2012; Accepted August 27, 2012; Published January 25, 2013)

Keywords: titanium (Ti), magnesium (Mg), fluoride, dental implant, corrosion resistance

\section{Introduction}

Ti has been selected as the dental material for implant devices, crowns, orthodontic wire and so on, because of its suitable mechanical properties, biocompatibility and corrosion resistance to body fluids. Besides, fluoride is well documented as anticariogenic agent showing the reduction of demineralization, the enhancement of remineralization, the interference of pellicle and plaque formation, the inhibition of microbial growth and metabolism, and others. ${ }^{1-4)}$ However, $\mathrm{Ti}$ has a nature to dissolve in fluoride solutions, so that there have been some reports regarding corrosion problem of the Ti dental devices. ${ }^{5-8)}$ One of the countermeasure to the problem is to develop a new $\mathrm{Ti}$ alloy corrosion-resistant to the fluoride solutions. Nakagawa et al. have researched corrosion behavior of several kinds of Ti alloys in the fluoride solutions, and found out Ti-Pt and Ti-Pd alloys which are good corrosion resistance in the solutions. ${ }^{9,10)}$ Our research group has also tried to develop a new Ti alloy exhibiting corrosion resistance in the fluoride solutions on the base of the following concept: A lot of metal fluorides are soluble in water. However there are some metal fluorides hard to dissolve in it. In the case that the metal forming insoluble fluoride is able to be alloyed with $\mathrm{Ti}$, the Ti alloy is expected to show excellent corrosion resistance in the fluoride solution due to forming almost insoluble film of the metal fluoride on the alloy surface, like fluoride-passivation. Table 1 shows solubility of metal fluoride hardly soluble in water. ${ }^{11)}$ The table indicates some of appropriate elements are in the second group of the periodic table. In the viewpoint, our research group had selected $\mathrm{Ca}$ as an additive element with $\mathrm{Ti}$ and successfully confirmed excellent corrosion resistance of $\mathrm{Ti}-$ $\mathrm{Ca}$ alloy in weak acid solutions containing fluoride ions. ${ }^{12)}$ This extensive research has focused on $\mathrm{Mg}$ as an additive

\footnotetext{
${ }^{* 1}$ Corresponding author, E-mail: haruna@kansai-u.ac.jp

${ }^{* 2}$ Graduate Student, Kansai University. Present address: Sumitomo Metal Ind. Ltd., Wakayama 640-8555, Japan

${ }^{* 3}$ Graduate Student, Kansai University. Present address: Mitsui Chemicals Inc., Omuta 836-8610, Japan
}

element alloyed with Ti. The aim of this paper is to develop the method for producing $\mathrm{Ti}-\mathrm{Mg}$ alloy, and to investigate corrosion behavior of the alloy in weak acid solutions containing fluoride ions.

\section{Experimental Procedure}

It is well known that a melting point of $\mathrm{Ti}\left(1668^{\circ} \mathrm{C}\right)$ is larger than a boiling point of $\mathrm{Mg}\left(1091^{\circ} \mathrm{C}\right)$, so the $\mathrm{Ti}-\mathrm{Mg}$ alloy cannot be produced by melting method such as conventional arc-melting. No existence of exact $\mathrm{Ti}-\mathrm{Mg}$ binary phase diagram may be caused by difficulty of the alloying. Therefore diffusion method was employed to produce the Ti-Mg alloy samples. Surfaces of dental implant devices may be attacked. So target of the research was to develop full bulk Ti-Mg alloy, not alloyed-surface Ti.

Pure Ti plate (commercial grade 2: H: 0.015, O: 0.095, N: 0.01 , Fe: 0.06 mass \%, Ti: bal) and granular $\mathrm{Mg}$ (99.9 mass\%) were prepared. Schematic illustration of the system for producing $\mathrm{Ti}-\mathrm{Mg}$ alloys is shown in Fig. 1. The $\mathrm{Mg}$ grains were put in the carbon crucible which was set in a vessel made of Type 304 stainless steel. One of the Ti plates was hanged in the $\mathrm{Mg}$, not to touch the carbon crucible. The other was put on the carbon crucible. A rid made of Type 304 stainless steel was welded to the vessel to seal it up. The sealed vessel was set in an electric furnace and its temperature was held at $950^{\circ} \mathrm{C}$ for 48,168 and $430 \mathrm{~h}$, followed by cooling in the furnace. Since $\mathrm{Mg}$ (melting point: $650^{\circ} \mathrm{C}$ ) melts and partially vaporizes in the sealed vessel at $950^{\circ} \mathrm{C}$, the one and the other $\mathrm{Ti}$ plates are exposed in liquid and vapor phases of $\mathrm{Mg}$, respectively. Then the process make $\mathrm{Mg}$ diffuse into the Ti plates from the surface to produce $\mathrm{Ti}-\mathrm{Mg}$ alloy. In this paper, we called 'dipping method' in which Ti was immersed in liquid $\mathrm{Mg}$, and 'vapor method' in which $\mathrm{Ti}$ was exposed in vapor $\mathrm{Mg}$.

The produced $\mathrm{Ti}-\mathrm{Mg}$ alloy was subjected to various tests using an optical microscope (BX51, Olympus Co.), an energy-dispersed spectroscope (EDS) equipped with a scanning electron microscope (SEM) (JSM-6060LV, JEOL 
Table 1 Solubility of metal fluoride in water. ${ }^{11)}$

\begin{tabular}{cccccccc}
\hline $\mathrm{CrF}_{3}$ & $\mathrm{AlF}_{3}$ & $\mathrm{NiF}_{2}$ & $\mathrm{CuF}_{2}$ & $\mathrm{CaF}_{2}$ & $\mathrm{MgF}_{2}$ & $\mathrm{CuF}_{2}$ \\
\hline $\mathrm{i}(\mathrm{s}: \mathrm{HF})$ & 0.50 & 2.50 & $7.5 \times 10^{-1}$ & $1.6 \times 10^{-2}$ & $1.3 \times 10^{-1}$ & $1.6 \times 10^{-1}$ \\
& & $\left(20^{\circ} \mathrm{C}\right)$ & $\mathrm{g} / \mathrm{L}$ & $\mathrm{g} / \mathrm{L}$ & $\mathrm{g} / \mathrm{L}$ & & \\
& & & & & \\
\hline
\end{tabular}

298 K, mass \%, i: insoluble, s: soluble

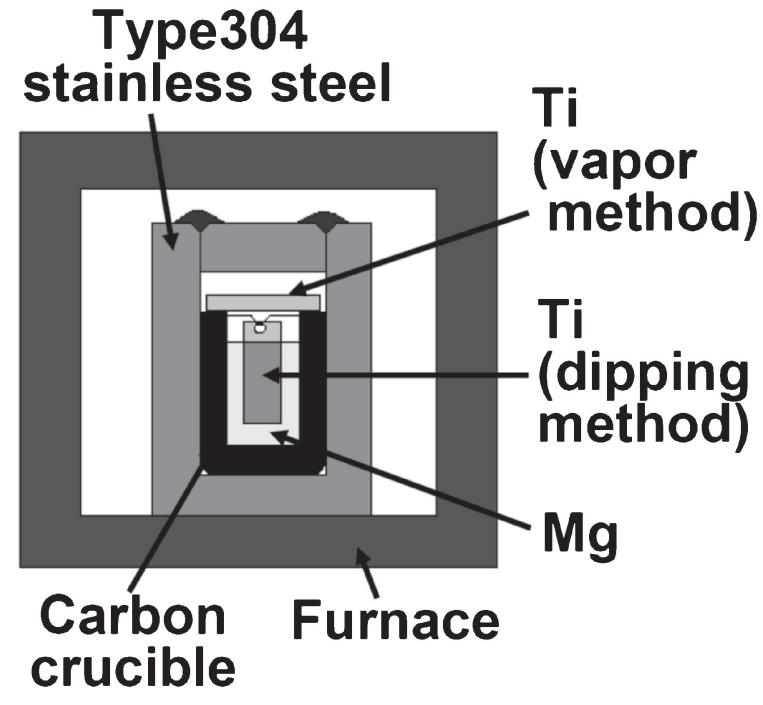

Fig. 1 Schematic illustration of the system for producing Ti-Mg alloy.

Ltd.), a Vickers micro hardness measurement apparatus (MXT- $\alpha$, Matsuzawa Co. Ltd.) and X-ray diffraction analyzer (RINT-2550, Rigaku Co.) to understand its microstructure, $\mathrm{Mg}$ concentration, hardness and lattice structure, respectively. In order to obtain cross sectional microstructure, the alloy was polished by buffing with alumina particles of $300 \mathrm{~nm}$ in diameter and etched with a HF solution of $\mathrm{pH} 3$.

Corrosion resistance was evaluated using electrochemical method. The as-alloyed specimen was immersed in boiled water to dissolve $\mathrm{Mg}$ adhered on the surface, and then the specimen surface was removed by a thickness of $0.05 \mathrm{~mm}$ by dry emery papers to \#6/0 to obtain flesh surface of the $\mathrm{Ti}-\mathrm{Mg}$ alloy. A lead wire was spot-welded to the specimen and the specimen was covered with the polytetrafluoroethilene tape in which an area of $6.0 \mathrm{~mm}$ diameter was removed to contact the metal surface with the test solution. Test solutions were prepared with reagents of $\mathrm{HF}$ and $\mathrm{NaF}$. Various pHs of the solutions were adjusted as an equilibrium $\mathrm{F}^{-}$concentration was fixed to $0.024 \mathrm{kmol} \mathrm{m}^{-3}$, corresponding to a concentration of general toothpaste (ca. $1000 \mathrm{ppm}$ ). Equilibrium concentrations of solutes were calculated with a dissociation constant of HF $\left(3.5 \times 10^{-4}\right.$ at $\left.25^{\circ} \mathrm{C}\right) .{ }^{11)} \mathrm{A} \mathrm{pH}$ of the prepared test solution was confirmed by a $\mathrm{pH}$ meter (F-51, Horiba Ltd.). The test solution was deaerated by $\mathrm{N}_{2}$ gas at least $0.5 \mathrm{~h}$ before and during the corrosion test described later. A temperature of the solution was kept at $25^{\circ} \mathrm{C}$. A potentiokinetic polarization test was carried out as a corrosion test using a potentiostat (PS-07, Toho Tech. Res. Co. Ltd.). A reaction cell had an $\mathrm{Ag} / \mathrm{AgCl}$ $\left(3.3 \mathrm{kmol} \mathrm{m}^{-3} \mathrm{KCl}\right)$ and a $\mathrm{Pt}$ electrodes as a reference and a counter electrodes, respectively. The specimen was
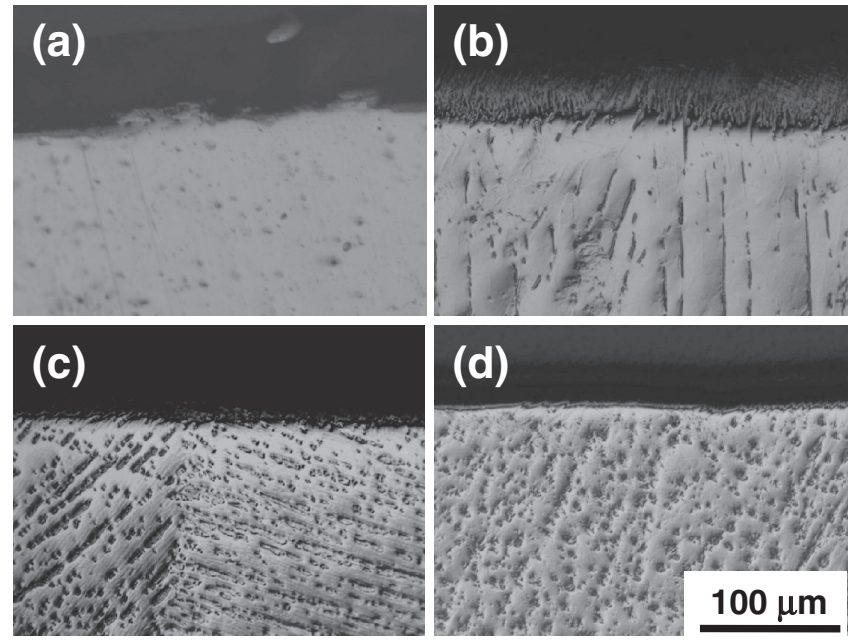

Fig. 2 Cross-sectional microstructures vicinity to the surface of the $\mathrm{Ti}-\mathrm{Mg}$ alloys produced by the vapor method for (a) 0, (b) 48, (c) 168 and (d) $430 \mathrm{~h}$.

immersed in the test solution, and a polarization curve of the system was measured from -2.0 to $+1.0 \mathrm{~V}_{\mathrm{Ag} / \mathrm{AgCl}}$ at $1.6 \mathrm{mV} \mathrm{s}^{-1}$.

The Ti-Mg alloy produced by vapor method for $430 \mathrm{~h}$ and immersed in the test solution of $\mathrm{pH} 4$ for $10 \mathrm{~h}$ was subjected to an X-ray photoelectron spectroscope (XPS) (XPS7000, Rigaku Co.) to confirm the chemical composition on just the surface of the alloy.

\section{Results and Discussion}

\subsection{Microstructure and lattice structure of specimen surface}

Figure 2 shows cross-sectional microstructures vicinity to the surfaces of the $\mathrm{Ti}-\mathrm{Mg}$ alloys produced by the vapor method for various holding times. Coarse acicular structure was observed in the specimen exposed for $48 \mathrm{~h}$, and as the time elapsed, the acicular phase became small and dense.

XRD patterns of the Ti-Mg alloy surfaces produced by vapor method for various holding times are shown in Fig. 3. Although the microstructure changed with the holding time, the XRD pattern was almost independent of the time. In addition, the patterns indicated that all the alloy exhibited the same lattice structure as $\alpha$-Ti. Some quite tiny peaks were found in the patterns but could not provide any material. The microstructure was also observed from the specimen produced by the same process without setting $\mathrm{Mg}$.

Time dependences of microstructure and lattice structure of the $\mathrm{Ti}-\mathrm{Mg}$ alloy produced by the dipping method were quite similar to those by the vapor method as described above. 


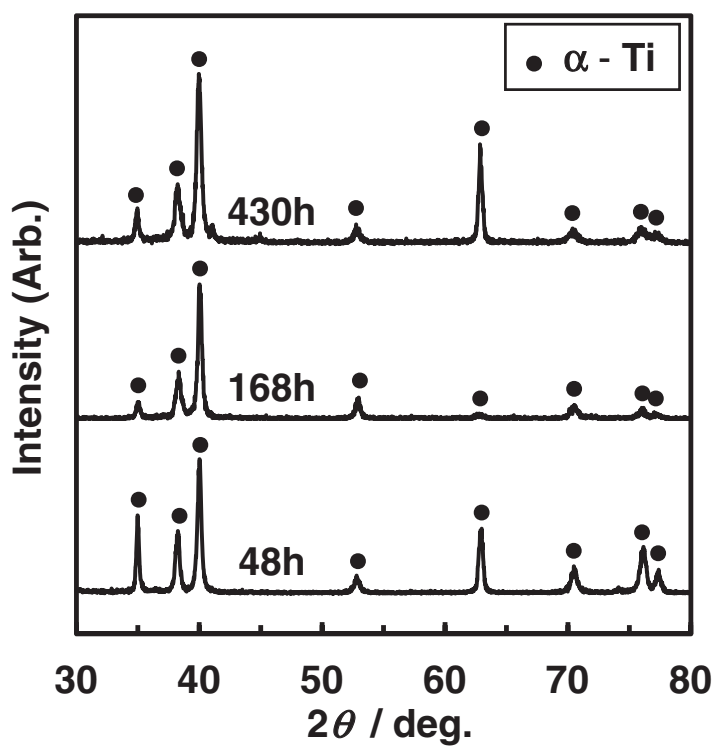

Fig. 3 XRD patterns of the Ti-Mg alloy surfaces produced by the vapor method for various holding times.

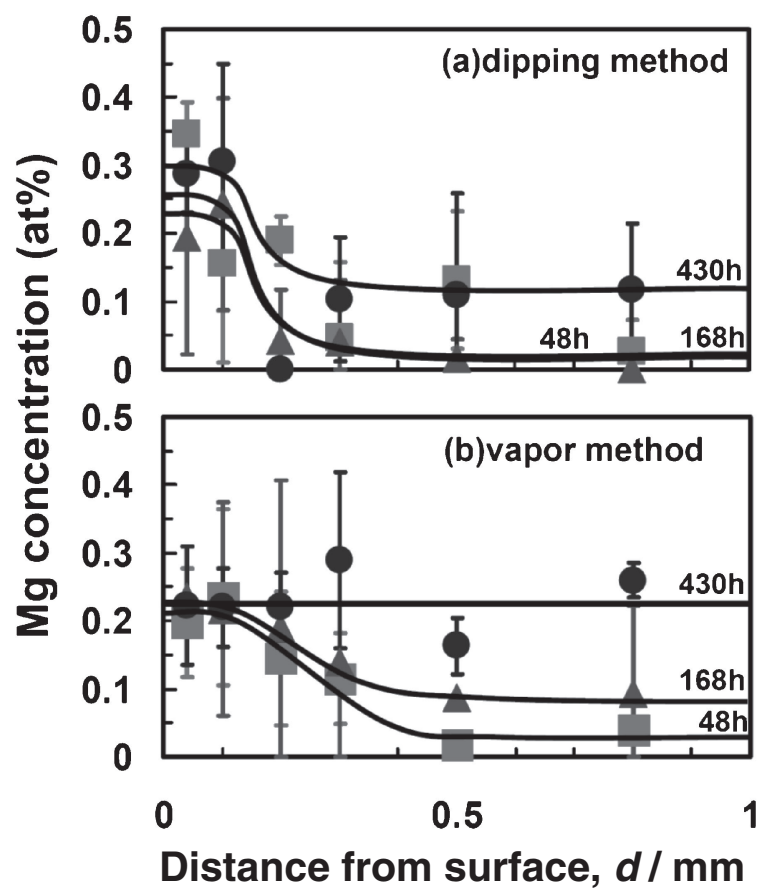

Fig. 4 Depth profiles of $\mathrm{Mg}$ concentration in the Ti-Mg alloys produced by (a) dipping and (b) vapor method as a function of holding time.

\subsection{Depth profile of Mg concentration}

Depth profiles of $\mathrm{Mg}$ concentration in the Ti-Mg alloys as a function of holding time are shown in Fig. 4. The concentration data were scattered because the measured values were near the detection limit (ca. 0.1 at $\%$ ) for the EDX apparatus. Therefore measurement was repeated by 3 times and an average with error bar were plotted in the figures. The error bar was their maximum and minimum values. In the case of the dipping method in Fig. 4(a), the profile in $48 \mathrm{~h}$ showed difference of $\mathrm{Mg}$ concentration at the surface and at the center; about 0.25 and almost 0 at\%, respectively. As the time elapsed to $430 \mathrm{~h}$, an $\mathrm{Mg}$ concentration at the surface was almost the same as 0.25 at\%, but that at a site deeper than

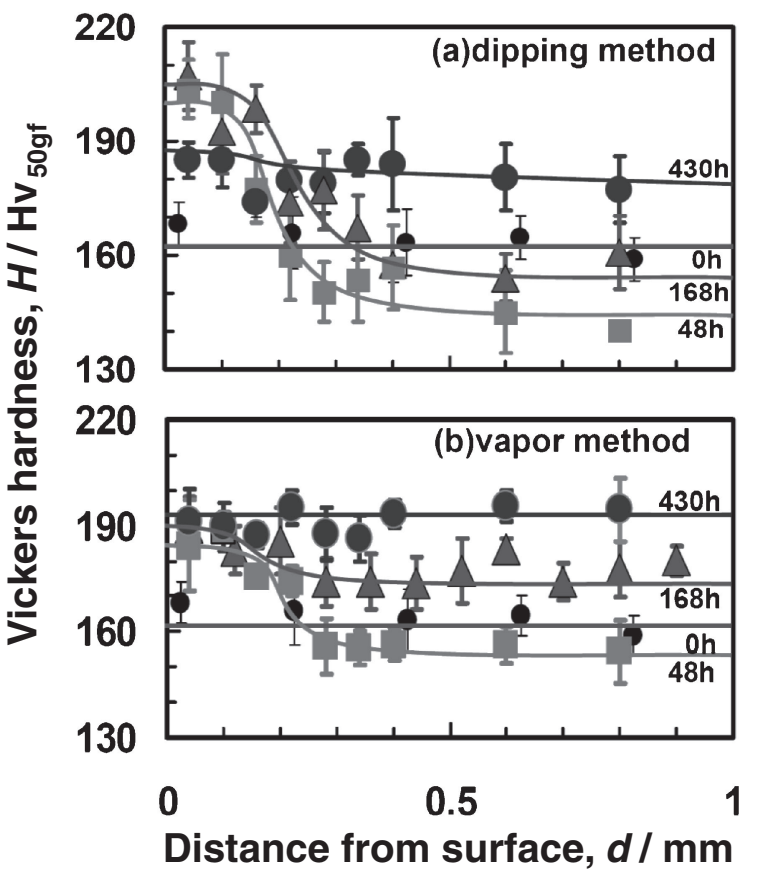

Fig. 5 Depth profiles of Vickers microhardness in the Ti-Mg alloys produced by (a) dipping and (b) vapor method as a function of holding time.

$0.30 \mathrm{~mm}$ increased to 0.10 at $\%$. However, no homogeneous distribution of $\mathrm{Mg}$ concentration was achieved even in a maximum holding time of $430 \mathrm{~h}$. In the case of the vapor method in Fig. 4(b), Mg concentration in $48 \mathrm{~h}$ was larger at the surface and smaller at the center of the specimen, similar to that in the dipping method. As the time elapsed, an $\mathrm{Mg}$ concentration at the surface within $0.1 \mathrm{~mm}$ was almost the same and was 0.22 at $\%$, but that at the center gradually increased. In $430 \mathrm{~h}, \mathrm{Mg}$ was distributed homogeneously over the specimen, and its concentration was 0.22 at $\%$. It was summarized from the findings that the vapor method successfully produced homogeneous $\mathrm{Ti}-\mathrm{Mg}$ alloy in relatively short time in comparison with the dipping method.

\subsection{Depth profile of hardness}

Figure 5 shows depth profiles of Vickers microhardness in the specimen as a function of holding time. Distribution of hardness in $\mathrm{Ti}$ before alloying was homogeneous and was $162 \mathrm{Hv}$. In the case of the dipping method in Fig. 5(a), a hardness in $48 \mathrm{~h}$ was $200 \mathrm{Hv}$ at the surface, steeply decreased with an increase in depth to $0.3 \mathrm{~mm}$, and then was about $145 \mathrm{Hv}$ at a depth of more than $0.3 \mathrm{~mm}$. Hardnesses at the surface and at the center sites were almost independent of and increased with an increase in holding time. In $430 \mathrm{~h}$, a hardness slightly diminished to $188 \mathrm{Hv}$ at the surface, and then gradually decreased with an increase in depth. In the case of the vapor method in Fig. 5(b), a holding time of $48 \mathrm{~h}$ induced hardness at the surface increase to about $190 \mathrm{Hv}$ and that at the center decrease to about $150 \mathrm{Hv}$. As the time elapsed, hardnesses at the surface and at the center were independent and increased, respectively. In $430 \mathrm{~h}$, distribution of hardness was finally homogeneous and about $190 \mathrm{Hv}, 1.2$ times larger than that of Ti. The trends of hardness profile were similar to that in the dipping method. 


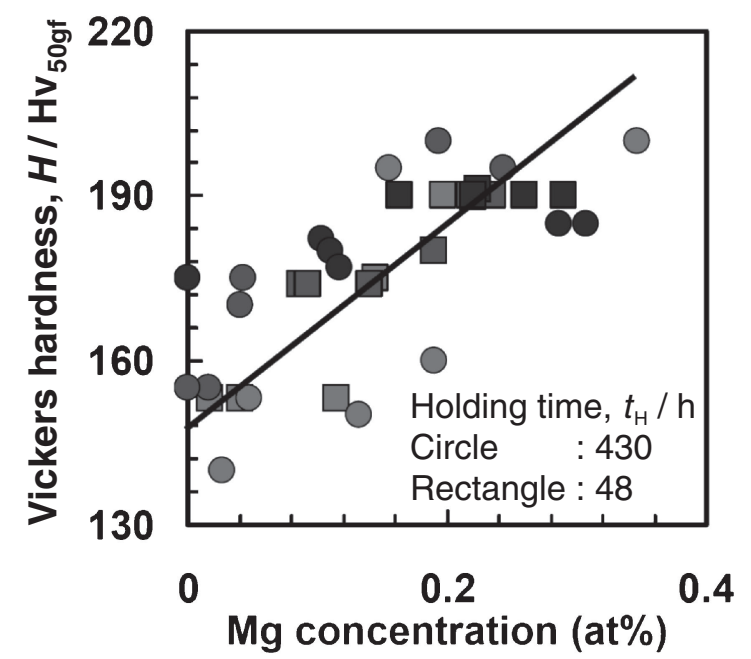

Fig. 6 Correlation between $\mathrm{Mg}$ concentration and hardness in the $\mathrm{Ti}-\mathrm{Mg}$ alloys.

From the two depth profiles of $\mathrm{Mg}$ concentration (Fig. 4) and hardness (Fig. 5), it is noted that the two parameters are correlated with each other. Therefore, a relation between the two parameters was analyzed. Figure 6 shows the correlation between $\mathrm{Mg}$ concentration and hardness at the same depth site. Although the data were scattered, there existed positive and almost linear relationship between the two parameters. Therefore, it can be concluded that $\mathrm{Mg}$ makes hardness of $\mathrm{Ti}$ increase by solid-solution hardening.

Hardnesses at the centers of the specimens produced for $48 \mathrm{~h}$ by both methods and for $168 \mathrm{~h}$ by the dipping method were lower than Ti before alloying. The reason is considered to be grain growth of the substrate $\mathrm{Ti}$ due to high process temperature of $950^{\circ} \mathrm{C}$.

\subsection{Selection of test solution for evaluating corrosion resistance}

In order to select the test solution for evaluating corrosion resistance of $\mathrm{Ti}-\mathrm{Mg}$ alloy, dependence of the corrosion behavior of $\mathrm{Ti}$ on $\mathrm{pH}$ of the fluoride solution was investigated.

Figure 7 shows polarization curves of $\mathrm{Ti}$ in the fluoride solutions of various $\mathrm{pHs}$. The polarization curve of Ti in the solution of $\mathrm{pH} 3$ was sectionalized by three parts of the potential region. The first was the 'cathodic potential region' from -2.0 to $-1.0 \mathrm{~V}_{\mathrm{Ag} / \mathrm{AgCl}}$ in which a current was negative and reduction reaction of proton to molecular hydrogen occurred. The second was 'anodic active dissolution (or corrosion) potential region' from -1.0 to $+0.5 \mathrm{~V}_{\mathrm{Ag} / \mathrm{AgCl}}$ in which a current was positive and larger corresponding to active dissolution of $\mathrm{Ti}$. The third was 'passive potential region' from +0.5 to $+1.0 \mathrm{~V}_{\mathrm{Ag} / \mathrm{AgCl}}$ in which a current was positive but smaller corresponding to suppression of the dissolution. Here a peak value of active dissolution current density was thought to be suitable for evaluation of the corrosion resistance, because active dissolution causes severe corrosion. As a $\mathrm{pH}$ ascended to 4 , a transition potential between active/passive states shifted in lower direction and then an active peak current density decreased. The solution of pH 5 and less made active dissolution completely sup-

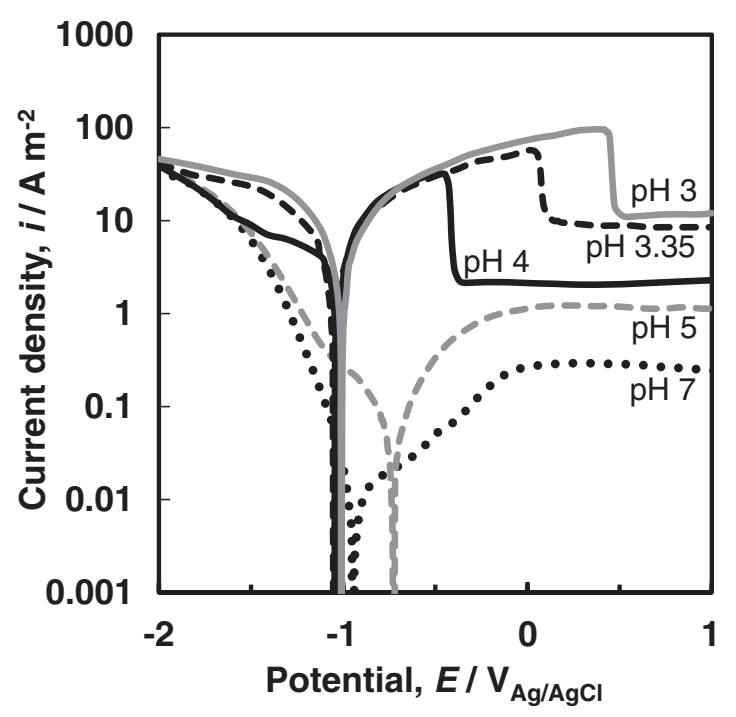

Fig. 7 Polarization curves of $\mathrm{Ti}$ in the fluoride solutions of various $\mathrm{pHs}$.

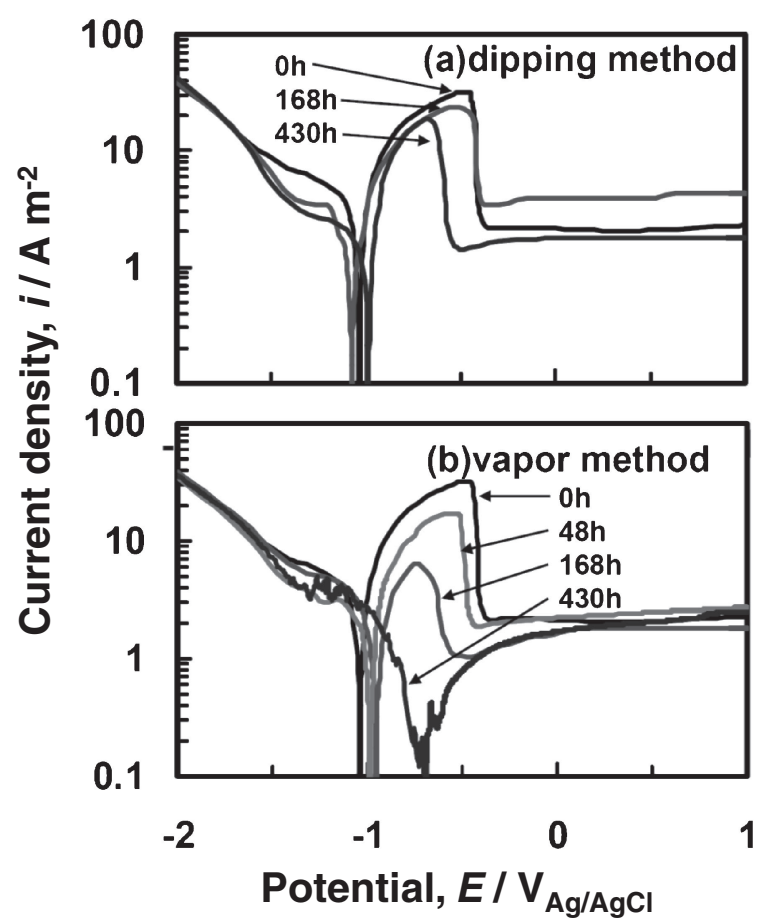

Fig. 8 Polarization curves of the Ti-Mg alloys produced by (a) dipping and (b) vapor method in the fluoride solution of $\mathrm{pH} 4$.

pressed, demonstrating that $\mathrm{Ti}$ exhibits good corrosion resistance in the fluoride solution of the $\mathrm{pH}$ near neutral.

From these findings, the fluoride solution of $\mathrm{pH} 4$ was selected as a test solution for evaluating corrosion resistance of $\mathrm{Ti}-\mathrm{Mg}$ alloy, because active dissolution current density should be obtained and $\mathrm{pH}$ of the test solution should be as near as human oral.

\subsection{Corrosion resistance in the fluoride solution}

In order to evaluate corrosion resistance of the $\mathrm{Ti}-\mathrm{Mg}$ alloy in the weak acid fluoride solution, polarization curves were measured. The results were summarized in Fig. 8. As can be seen in Fig. 8(a), Ti (' $0 \mathrm{~h}$ ' in the figure) before alloying showed active dissolution state clearly. This means that $\mathrm{Ti}$ 


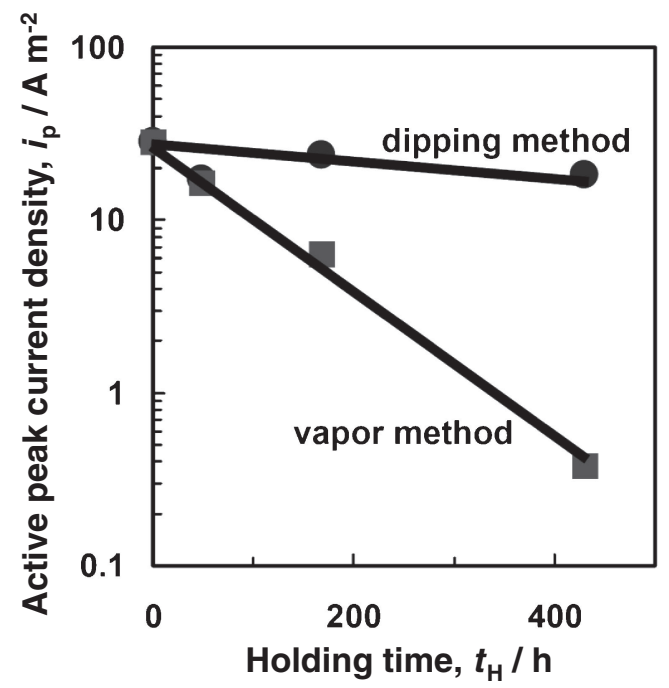

Fig. 9 Effect of holding time in producing $\mathrm{Ti}-\mathrm{Mg}$ alloy on active peak current density.

severely corrodes in the fluoride solution. Any polarization curves of the $\mathrm{Ti}-\mathrm{Mg}$ alloys produced by the dipping method were similar to that of Ti. However, only the specimen in $430 \mathrm{~h}$ showed slight negative shift of a transition potential between active/passive states and small decrease of an active peak current density. In Fig. 8(b), on the other hand, the specimens produced by the vapor method demonstrated remarkable negative shift of a transition potential and tremendous decrease of an active peak current density with an increase in holding time. It is emphasized that there was no active dissolution from the specimen in $430 \mathrm{~h}$, meaning that the $\mathrm{Ti}-\mathrm{Mg}$ alloy is passivated when naturally immersed even in the weak acid fluoride solution.

Effect of holding time on active peak current density is shown in Fig. 9. It is obvious that logarithms of active peak current density in the dipping and the vapor methods gradually and steeply decrease with an increase in holding time, respectively, and these relationships in both methods were almost linear. The current densities of the $\mathrm{Ti}-\mathrm{Mg}$ alloy produced by the dipping and the vapor methods for $430 \mathrm{~h}$ were 0.58 and 0.012 times against that for $\mathrm{Ti}$, respectively. In the other words, the $\mathrm{Ti}-\mathrm{Mg}$ alloy produced by the vapor method exhibits excellent corrosion resistance in the weak acid fluoride solution by about 80 times than pure Ti. The large difference in active peak current density between the two methods was remarkable, and the reason is now discussing.

\subsection{Surface analysis of the alloy immersed in the fluoride solution}

Two Ti-Mg alloys produced by the vapor method for $430 \mathrm{~h}$ and mechanically polished were prepared. One was immersed in the fluoride solution of $\mathrm{pH} 4$ for $10 \mathrm{~h}$, and rinsed by distilled water. The as-polished and the immersed specimens were subjected to the XPS analysis. XPS profiles of Mg2p and F1s for the specimen without and with immersion are shown in Fig. 10. There was no remarkable existence of $\mathrm{Mg}$ on the surface of the specimen without immersion from Fig. 10(a). On the other hand, signals of $\mathrm{Mg}$ and $\mathrm{F}$ were slightly detected from the specimen with immersion as shown
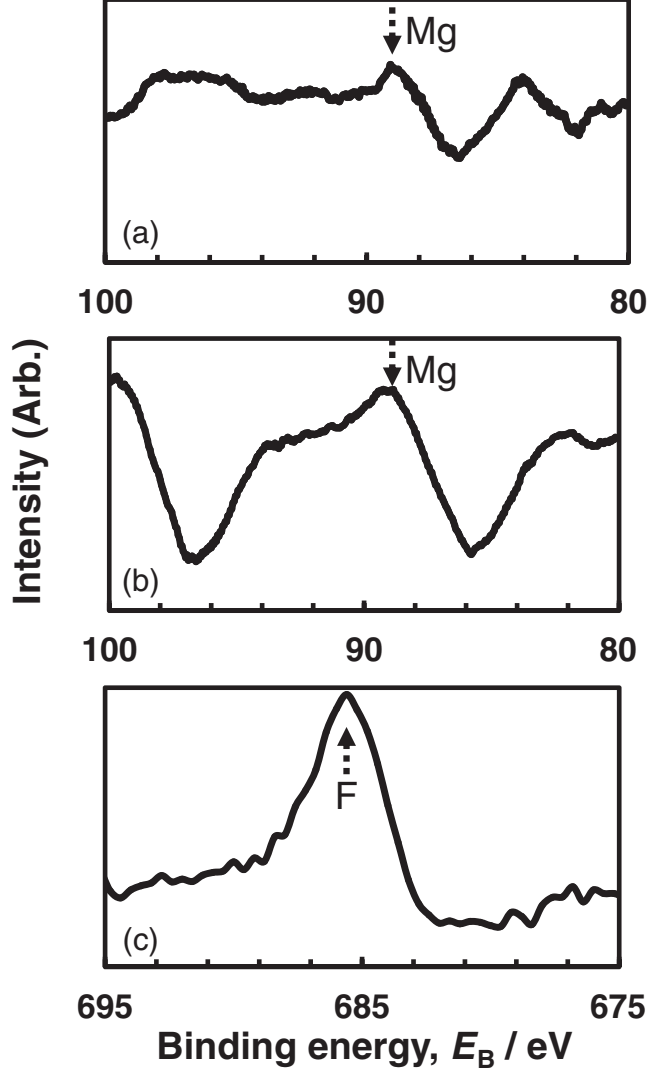

Fig. 10 XPS profiles of (a) and (b) Mg2p and (c) F1s obtained from the Ti$\mathrm{Mg}$ alloy (a) without and (b) and (c) with immersion in the fluoride solution of $\mathrm{pH} 4$ for $10 \mathrm{~h}$.

in Figs. 10(b) and 10(c), respectively. Since the specimen was naturally passivated in the solution, the results of XPS analysis suggested that the $\mathrm{Ti}-\mathrm{Mg}$ alloy was naturally covered with passive film of $\mathrm{Mg}$ fluoride (ex. $\mathrm{MgF}_{2}$ ) to prevent active dissolution even in the weak acid fluoride solution.

\section{Conclusions}

(1) $\mathrm{Ti}-\mathrm{Mg}$ alloys were successfully produced by the two methods at $950^{\circ} \mathrm{C}$; one was that $\mathrm{Ti}$ was immersed in liquid $\mathrm{Mg}$ phase, and the other was that Ti was exposed in vapor $\mathrm{Mg}$ phase.

(2) In both methods, $\mathrm{Mg}$ diffused into the $\mathrm{Ti}$ plate gradually. In the vapor method for $430 \mathrm{~h}, \mathrm{Mg}$ distributed homogeneously over the Ti plate of $2 \mathrm{~mm}$ thickness.

(3) Depth profile of hardness in the alloy almost corresponded to that of $\mathrm{Mg}$ concentration. Hardness increased almost linearly with an increase in $\mathrm{Mg}$ concentration.

(4) $\mathrm{Ti}-\mathrm{Mg}$ alloys exhibited corrosion resistance in the weak acid fluoride solution in comparison with pure Ti. The vapor method at $950^{\circ} \mathrm{C}$ for $430 \mathrm{~h}$ made the $\mathrm{Ti}-\mathrm{Mg}$ alloy the best corrosion resistance by 80 times than that of pure Ti.

(5) The results of XPS analysis suggested that the Ti-Mg alloy was naturally covered with passive film of $\mathrm{Mg}$ fluoride to prevent active dissolution even in the weak acid fluoride solution. 


\section{REFERENCES}

1) O. Fejerskov and B. H. Clarkson: Fluoride in Dentistry, ed. by O Fejerskov, J. Ekstrand and B. A. Burt, (Munksgaard, Copenhagen, 1996) pp. 187-213.

2) G. Rolla and J. Ekstrand: Fluoride in Dentistry, ed. by O. Fejerskov, J. Ekstrand and B. A. Burt, (Munksgaard, Copenhagen, 1996) pp. 215 229.

3) R. Hamilton and G. H. W. Bowden: Fluoride in Dentistry, ed. by O. Fejerskov, J. Ekstrand and B. A. Burt, (Munksgaard, Copenhagen, 1996) pp. 230-251.

4) J. M. ten Cate and J. D. M. Featherstone: Fluoride in Dentistry, ed. by O. Fejerskov, J. Ekstrand and B. A. Burt, (Munksgaard, Copenhagen, 1996) pp. 252-272.
5) H. S. S. Siirila and M. Kononen: Int. J. Oral Maxillofac. Implants 6 (1991) 50-54.

6) L. Probster, W. Lin and H. Hutteman: Int. J. Oral Maxillofac. Implants 7 (1992) 390-394.

7) G. Boere: J. Appl. Biomater. 6 (1995) 283-288.

8) F. Toumelin-Chemla, F. Rouelle and G. Burdairon: J. Dent. 24 (1996) 109-115.

9) M. Nakagawa, Y. Matono, S. Matsuya, K. Udoh and K. Ishikawa: Biomaterials 26 (2005) 2239-2246.

10) Y. Matono, M. Nakagawa, S. Matsuya, K. Ishikawa and Y. Terada: Dent. Mater. J. 25 (2006) 104-112.

11) Handbook of Chemistry -Fundamentals, fifth edition, ed. by The Chemical Society of Japan, (Maruzen, Tokyo, 2004) pp. 153-155.

12) T. Haruna and I. Shinohara: Mater. Sci. Forum 638-642 (2010) 564569. 